\title{
Benign familial haematuria in children from the Jewish communities of Israel: clinical and genetic studies
}

\author{
BELLA EISENSTEIN, HARRY STARK, AND RICHARD M. GOODMAN \\ From the Paediatric Nephrology Unit, Beilinson Medical Center; the Department of Human Genetics, \\ The Chaim Sheba Medical Center; and the Sackler School of Medicine, Tel-Aviv University, Israel
}

SUMMARY Over 7 years, 130 children were referred for prolonged isolated haematuria of unknown cause. In 34 instances, haematuria was also found in one or more family members. In 23 of these families (18\% of all referrals for isolated haematuria), investigation and follow-up, for periods of 5 to 10 years, of the index cases and of 56 haematuric relatives showed no evidence of renal disease and no other pathological findings. These subjects were diagnosed as having benign familial haematuria.

The gene for benign familial haematuria is apparently transmitted as an autosomal dominant with reduced penetrance and variable expressivity. In Israel, the disorder seems to be more frequent among Jews of non-Ashkenazi descent than among those of European ancestry (Ashkenazim).

Persistent or recurrent microscopical haematuria in otherwise healthy children represents a rather common clinical problem necessitating diagnostic procedures to identify or rule out renal disease, urinary tract pathology, or a haemorrhagic diathesis. Often, such examinations fail to reveal any cause for the haematuria. Many investigators (Baehr, 1926; Livaditis and Ericsson, 1962; Travis et al., 1962; Arneil et al., 1969; Johnston and Shuler, 1969; Glasgow et al., 1970) have concluded that the majority of such patients do not suffer from renal disease and have conferred upon them such diagnoses as 'idiopathic', 'benign', or 'essential' haematuria. In 1965, Ayoub and Vernier first reported a familial incidence of benign haematuria, a finding which has since been substantiated by others (McConville et al., 1966; Marks and Drummond, 1969; Rogers et al., 1973; Cotton et al., 1975). Since familial aggregation appeared to be a surprisingly common occurrence among children referred to our clinic because of persistent or recurrent haematuria, we decided to investigate all such cases seen over a 7-year period. Of these patients, 23 are believed to have benign familial haematuria (BFH). This paper describes the features on which the diagnosis was based and summarises clinical and genetic findings in this group of subjects.

Received for publication 23 December 1978

\section{Subjects and methods}

During the period 1966 to 1972,130 children were seen in the Paediatric Nephrology Clinic of the Beilinson Medical Center with isolated, asymptomatic, persistent, or recurrent haematuria for which no cause could be found. This was defined as the finding of more than 10 erythrocytes per highpower field in $80 \%$ or more of repeated urine examinations performed over a period of at least one year, and Addis counts showing more than 1.5 million erythrocytes per $12 \mathrm{~h}$ (our findings in healthy children are less than 0.5 million). In such cases urine analyses were performed on members of the immediate family (sibs and parents) and a family history was taken relating to renal disease, urinary findings, hypertension, deafness, and ocular anomalies. In 34 instances, haematuria was discovered in one or more members of the patient's family as a result of this search.

The following investigations were performed on each of these 34 patients: physical examination, repeated urine testing and urine cultures, chromatographic examination of urine for amino-acids, serum chemistries, studies of haemostatic function, endogenous creatinine clearance, ASLO titre, serum complement (C3), anti-nuclear factor, LE cells, intravenous urography, and audiometry. Cystography, cystoscopy, retrograde pyelography, and 
renal biopsy were performed only in isolated cases because of the invasive nature of these investigations.

All parents and sibs with haematuria, as well as some distant relatives with this finding, underwent physical examination and serum chemistry determinations, including urea nitrogen and creatinine. In addition, creatinine clearances were performed in 20 of the relatives, intravenous urography in 12, and audiometric studies in 25 .

\section{Results}

Among a total of 130 children investigated for unexplained persistent or intermittent haematuria, familial haematuria involving two to eight members of the same family was discovered in 34 instances. In 11 of these families, associated findings in one or more subjects suggested diagnoses other than BFH, including that of familial nephritis. These findings included: reduced renal function, sensory hearing defects, proteinuria of over $500 \mathrm{mg} / 24 \mathrm{~h}$, hypocomplementaemia, and hyperuricaemia. Of the 11 index cases in this group, two have, in fact, shown deterioration of renal function with biopsy evidence of progressive glomerular and interstitial changes.

The remaining 23 children and their families showed no evidence of renal disease, apart from haematuria, and no other pathological findings. These are the patients diagnosed as having benign familial haematuria on whom this study is based. As summarised in Table 1 , of the 130 children referred to our service with unexplained haematuria, the finding was familial in $26 \%$, while a final diagnosis of BFH was made in $18 \%$. Table 2 summarises findings in this latter group of children as regards age at diagnosis, sex, duration of observed haematuria, and number of haematuric relatives observed. Among the 56 relatives with haematuria, this finding was in most cases only discovered during the investigation of the proband. In several instances

Table 1 Familial incidence of haematuria

\begin{tabular}{lrr}
\hline Children with unexplained haematuria & 130 & $(100 \%)$ \\
$\begin{array}{l}\text { Patients with 1 or more haematuric relatives } \\
\text { Families with haematuric subjects showing }\end{array}$ & 34 & 11 \\
$\begin{array}{l}\text { additional pathology } \\
\begin{array}{l}\text { Children diagnosed as benign familial } \\
\text { haematuria }\end{array}\end{array}$ & 23 & $(8 \%)$ \\
\hline
\end{tabular}

Table 2 Data on 23 cases of benign familial haematuria

\begin{tabular}{|c|c|c|c|c|c|c|c|}
\hline \multicolumn{4}{|c|}{ Proband } & \multicolumn{4}{|l|}{ Relatives } \\
\hline $\begin{array}{l}\text { Sex } \\
M\end{array}$ & $F$ & $\begin{array}{l}\text { Age at } \\
\text { investiga- } \\
\text { tion }(y)\end{array}$ & $\begin{array}{l}\text { Age at } \\
\text { detection } \\
(y)\end{array}$ & $\begin{array}{l}\text { Duration } \\
\text { of follow- } \\
\text { up }(y)\end{array}$ & $\begin{array}{l}\text { No of } \\
\text { affected } \\
\text { relatives }\end{array}$ & $\begin{array}{l}\text { Sex } \\
M\end{array}$ & $F$ \\
\hline 8 & 15 & $9 \frac{1}{2}-18 \frac{1}{2}$ & $1 \frac{1}{2}-13$ & $5-10$ & 56 & 25 & 31 \\
\hline
\end{tabular}

its presence had been noted for periods of years. Haematuria is more common in females than i $\overrightarrow{\overrightarrow{7}}$ males $(1 \cdot 5: 1)$. In only five cases was the haematurit macroscopic, in one case persistently so for fouf years. Microscopical haematuria was constant in 36.5. subjects and intermittent in 38 ; in five famil $\bar{\not}$ members insufficient urine analyses were performe \& to determine constancy of the finding. Proteinuriag was absent or minimal ( $<200 \mathrm{mg} / 24 \mathrm{~h}$ ), two families with severe proteinuria having been excluded by definition.

Physical examination was non-contributory an blood pressure was normal in all probands an affected relatives. Blood counts, haemostatic func $\overline{\bar{\sigma}}$ tion, blood chemistry, serum complement (C3) and ASLO titres were within normal limits. Antif nuclear factor and LE cells were absent in all cases? Creatinine clearances varied between 82 and 14 \& $\mathrm{ml} / \mathrm{min} / 1.73 \mathrm{~m}^{2}$. Audiometry was normal in aft 48 subjects examined. Intravenous urography wa\& completely normal in 30 cases and in five showe $\Phi$ minor anatomical abnormalities which could noo explain the haematuria. The one retrograde pyelography, three cystographies, and two cystoscopieș performed were normal.

Five kidney biopsies were performed on foub children, including two biopsies in a girl wit persistent macroscopic haematuria. The indicatio

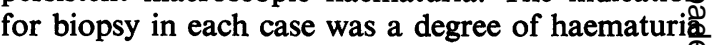
or proteinuria or both greater than that seen in the majority of cases. Light microscopy showed $n \vec{\phi}$ glomerular abnormalities. In two instances pers glomerular fibrosis was seen in a single glomerulus (of a total of 11 and 20 glomeruli, respectively) an $\bar{\phi}$ one specimen showed two small areas of interstitial

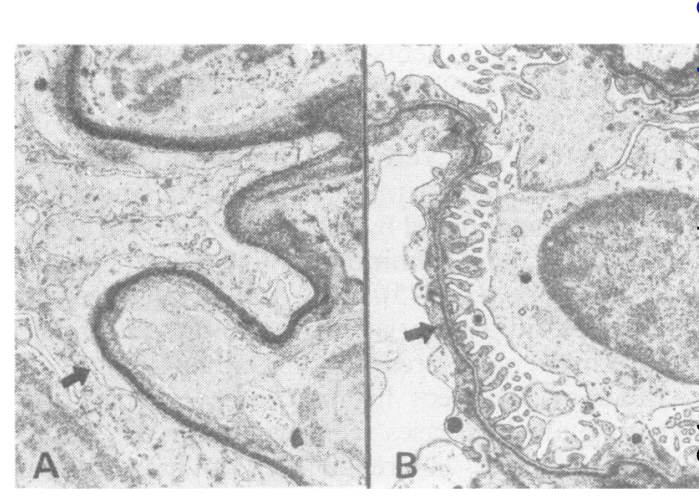

Fig. 1 A. Electron micrograph of 10-year-old child with normal glomeruli. B. Electron micrograph of 9-year-old child with benign familial haematuria. Note marked thinning of lamina densa compared to normal glomerulus (arrows). (PAS-methenamine silver. Original magnification $\times 3300)$. 
fibrosis. Electron microscopy was performed in only two instances, both of which showed a focal thinning of the glomerular basement membrane, and especially of the lamina densa (Fig. 1), similar to that first described by Rogers et al. (1973) in patients with BFH. Although described by other authors in cases of familial and non-familial benign haematuria, this is considered to be a non-specific finding (Hill et al., 1974).

The 23 children have been followed up for periods of 5 to 10 years. During this time no significant changes in urinary findings or renal function were seen in either the index cases or their haematuric relatives.

\section{Genetic aspects}

Abbreviated family pedigrees of affected probands are shown in Fig. 2. Of the 23 families examined, three families had affected members in three generations, 16 had two generations affected, while in four families only two children in the same generation were affected. Consanguinity was present in five families, three of which originated from Iraq, the

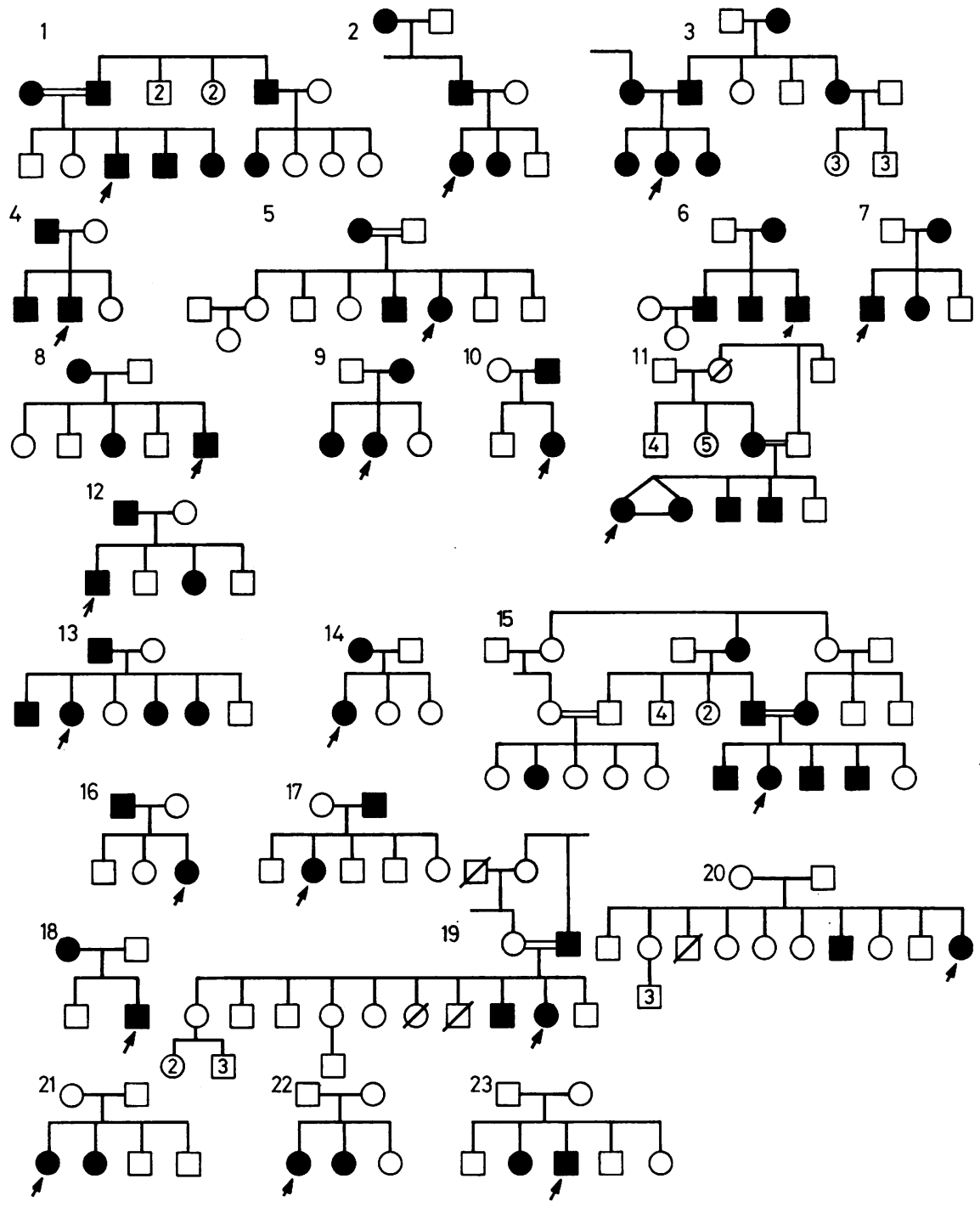

Fig. 2 Abbreviated family pedigrees of 23 probands with benign familial haematuria. 
other two originating from Morocco and Afghanistan. All three of these Jewish communities are known to have relatively high rates of consanguinity. Of the 83 affected subjects, 48 were females and 35 were males. In several families there was male to male transmission. These observations suggest that the most likely mode of transmission is autosomal dominant with reduced penetrance and variable expressivity.

A study of the ethnic distribution of this trait among the Jewish communities of Israel showed that of the 23 affected families, $18(78 \%)$ were of nonAshkenazi (Asian/African) descent, while five families (22\%) were of Ashkenazi (European) origin. Of the former group, eight families (35\%) were of Iraqi ancestry. Since the ratio of Ashkenazi to non-Ashkenazi among Jewish children admitted to Beilinson Hospital is approximately $1: 2$, it would appear that BFH is more common among the nonAshkenazi Jewish communities. This disorder was not observed among Arab children in our clinic, a finding that may reflect the small number of Arab children seen as outpatients in our hospital. Additional studies are needed to assess properly the ethnic distribution of this trait in Israel.

\section{Discussion}

Although the entity of benign haematuria is well recognised, clinicians often hesitate to make this diagnosis for fear of missing organic renal disease. The familial occurrence of benign haematuria is generally considered to be rare and a search for isolated microscopical haematuria among family members is often neglected. In our experience, this simple investigation, performed in 130 children with no family history of renal disease, showed a familial occurrence of haematuria in $34(26 \%)$. Further studies of these families led us to believe that $23 \mathrm{had}$ BFH. Thus, in the population served by our clinic, approximately 1 in 5 children with haematuria of unknown cause probably suffers from benign familial haematuria.

The finding of haematuria in a single relative could, of course, be coincidental and unrelated to the cause of haematuria in the patient under investigation. Alternatively, the presence of haematuria in a number of family members may suggest the much rarer diagnosis of familial nephritis. In many cases, however, a careful family history and investigation of all the haematuric subjects would allow a diagnosis of BFH to be made with a moderate degree of confidence. Nevertheless, it is strongly suggested that all such subjects should remain under permanent medical supervision, as a benign course cannot be predicted with certainty.

A number of previous studies have described a frequency of familial haematuria equal to, of greater than, that found in our population (Ayoub $\overrightarrow{5}$ and Vernier, 1965; McConville et al., 1966; Johnston? and Shuler, 1969; Cotton et al., 1975). In contrast other workers have found a familial aggregation to be rare among children with idiopathic haematuria (Arneil et al., 1969; Glasgow et al., 1970). All these? studies had rather small numbers of patients. Theren have been no studies of gene frequencies for this trait among different populations. The considerabledifferences we found among Jewish communities in $\vec{w}$ Israel suggest that similar differences in incidence? may be found among other ethnic groups. The auto somal dominant transmission of BFH noted in our study is in agreement with the findings of otheE authors (McConville et al., 1966; Rogers et al., 1973)i w

We believe that in cases of isolated, prolongedo haematuria considerable effort should be made to establish clearly (or exclude) the diagnosis of BFH. This diagnosis will assist the physician in providing a prognosis and appropriate genetic counselling.

\section{References}

Arneil, G. C., Lam, C. N., McDonald, A. M., and McDonald $\overrightarrow{0}$ M. (1969). Recurrent haematuria in 17 children. British Medical Journal, 2, 233-235.

Ayoub, E. M., and Vernier, R. L. (1965). Benign recurrent hematuria. American Journal of Diseases of Children, 109 217-223.

Baehr, G. (1926). Benign and curable form of hemorrhagion nephritis. Journal of the American Medical Association 86, 1001.

Cotton, J. R., Schwartz, M. M., Antonovych, T. T., anc Hunsicker, L. K. (1975). Benign familial hematuria? frequency studies in 12 families. (Abst.) Kidney International, 8, 408.

Glasgow, E. F., Moncrief, M. W., and White, R. H. R. (1970)? Symptomless haematuria in childhood. British Medicat Journal, 2, 687-692.

Hill, G. S., Jenis, E. H., and Goodloe, S. (1974). The non: specificity of the ultrastructural alterations in hereditary nephritis. Laboratory Investigation, 31, 516-532.

Johnston, C., and Shuler, S. (1969). Recurrent haematuriå in childhood: a five year follow-up. Archives of Disease in Childhood, 44, 483-486.

Livaditis, A., and Ericsson, N. O. (1962). Essential hematuria in children: prognostic aspects. Acta Paediatrica, 51 630-634.

McConville, J. M., West, C. P., and McAdams, A. J. L (1966). Familial and non-familial benign hematuriaos

Journal of Pediatrics, 69, 207-214.
Marks, M. I., and Drummond, K. N. (1969). Benign familia 5 , hematuria. Pediatrics, 44, 590-593.

Rogers, P. M., Kurtzmann, N. A., Bunn, S. N., and White M. G. (1973). Familial benign essential hematuria. Archives of Internal Medicine, 131, 257-262.

Travis, L. B., Daeschner, C. W., Dodge, W. F. Hopps, H. C. $\overline{\mathrm{D}}$ and Rosenberg, H. S. (1962). 'Idiopathic' hematuria? Journal of Pediatrics, 60, 24-32.

Requests for reprints to Dr Harry Stark, Paediatricon Nephrology Unit, Beilinson Medical Center, Petah? Tiqva, Israel. 